\title{
Is it Safe to Perform Cardiac Catheterizations on Adults With Congenital Heart Disease in a Pediatric Catheterization Laboratory?
}

\author{
Swati Garekar, ${ }^{1}$ MD, Melissa M. Paules, ${ }^{2}$ Surendranath V. Reddy, ${ }^{3}$ MD, Daniel R. Turner, ${ }^{1}$ MD, \\ Sanjeev Sanjeev, ${ }^{1}$ MD, Joshua Wynne, ${ }^{4}$ MD, Michael L. Epstein, ${ }^{1}$ MD, Peter P. Karpawich, ${ }^{1}$ MD, \\ Robert D. Ross, ${ }^{1} \mathrm{MD}$, and Thomas J. Forbes, ${ }^{1 *} \mathrm{MD}$
}

\begin{abstract}
Objective: To determine the complication rate during the catheterization in adults with congenital heart disease (CHD) in a pediatric catheterization laboratory (PCL). Background: An increasing number of patients with $\mathrm{CHD}$ are surviving into adulthood, with diagnostic and interventional cardiac catheterization being essential for the management of their disease. The complication rate during the catheterization of adults with CHD has not been reported. Methods: A retrospec-

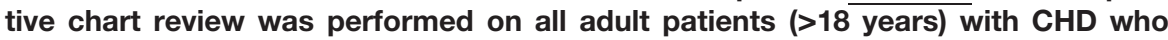
underwent diagnostic or interventional catheterization in our PCL within the past 8.5 years. Results: A total of 576 procedures were performed on 436 adult patients (median age 26 years). Complex heart disease was present in 387/576 $(67 \%)$ procedures. An isolated atrial septal defect or patent foramen ovale was present in $115 / 576(20 \%)$ procedures, and 51/576 (9\%) procedures were performed on patients with structurally normal hearts with arrhythmias. Interventional catheterization was performed in $378 / 576(66 \%)$ procedures. There were complications during 61/576 (10.6\%) procedures; 19 were considered major and 42 minor. Major complications were death (1), ventricular fibrillation (1), hypotension requiring inotropes (7), atrial flutter (3), retroperitoneal hematoma, pneumothorax, hemothorax, aortic dissection, renal failure, myocardial ischemia and stent malposition (1 each). The most common minor complications were vascular entry site hematomas and hypotension not requiring inotropes. Procedures performed on patients $\geq 45$ years of age had a $19 \%$ occurrence of complications overall compared with $9 \%$ occurrence rate in patients of age $<45$ years $(P<$ 0.01). Conclusions: The complication rate during the catheterization of adults with CHD in a PCL is similar to the complication rate of children with CHD undergoing cardiac catheterization. The older subset of patients are more likely to encounter complications overall. The encountered complications could be handled effectively in the PCL. With screening in place, it is safe to perform cardiac catheterization on most adults with CHD in a PCL. 02005 Wiley-Liss, Inc.
\end{abstract}

Key words: congenital heart disease; cardiac catheterization; complications

\section{INTRODUCTION}

During the last two decades, dramatic advances have been made in the management of congenital heart disease (CHD). Approximately $85 \%$ of infants born today with CHD are expected to live into adulthood [1-5]. Many of these adult patients will require diagnostic or interventional cardiac catheterization for management of their CHD. Furthermore, adults with atrial septal defect (ASD) and patent foramen ovale (PFO) are

\footnotetext{
${ }^{1}$ Division of Cardiology, Children's Hospital of Michigan, Wayne State University, Detroit, Michigan

${ }^{2}$ Central Michigan University, Mount Pleasant, Michigan

${ }^{3}$ Department of Pediatrics, Hurley Medical Center, Michigan

State University, Flint, Michigan

${ }^{4}$ Division of Cardiology, Harper Hospital, Wayne State University, Detroit, Michigan
}

Joshua Wyne's current affiliation is department of Internal Medicine, University of North Dakota, North Dakota, USA.
*Correspondence to: Thomas J. Forbes, 3901 Beaubien Blvd, Children's Hospital of Michigan, Division of Pediatric Cardiology, Detroit, MI 48201. E-mail: tforbes@dmc.org

Received 28 April 2005; Revision accepted 28 July 2005

DOI $10.1002 / \mathrm{ccd} .20537$

Published online 7 October 2005 in Wiley InterScience (www. interscience.wiley.com). 
undergoing cardiac catheterization for percutaneous closure of these defects [6]. Although the safety of performing catheterization in pediatric and adult patients has been reported, there is no data on the complication rate in performing cardiac catheterization in adults with CHD. The following study evaluates the overall complication rate during diagnostic and therapeutic cardiac catheterization of adults with CHD in a pediatric catheterization laboratory (PCL).

\section{METHODS}

A retrospective chart review was performed on all patients aged $\geq 18$ years who underwent cardiac catheterization in our PCL situated in a free-standing children's hospital, between January 1996 and October 2004. Technical and nursing staffs in the PCL were ACLS certified. Informed consent was obtained prior to the catheterization in all patients. Patients older than 30 years were initially screened by either an adult or pediatric cardiologist for evidence of ongoing ischemic heart disease with a complete medical history, electrocardiogram, echocardiogram, and stress testing as applicable. Patients with poorly controlled ischemic heart disease were referred to an adult cardiologist for management of the ischemic heart disease; after which they could be sent back to the PCL for the procedure. Patient age, weight, gender, diagnosis, history of arrhythmias, hypertension, stroke, NYHA classification, and other comorbid conditions were noted. Diagnoses were classified into complex CHD, minor CHD (ASD/PFO/patent ductus arteriosus/ aorto-pulmonary collaterals), or anatomically normal hearts with arrhythmias. The procedures were classified as either diagnostic or interventional. Complications associated with the catheterization were considered major (unanticipated complications within $24 \mathrm{hr}$ of the procedure that required intervention, close observation, or resulted in death) or minor (all other complications). Arrhythmias occurring during electrophysiology study or with catheter manipulation were not included. Other data including use of general anesthesia and length of hospital stay were noted. Patients were arbitrarily divided into two groups based on age (group 1: patients $<45$ years of age, and group 2: patients $\geq 45$ years of age).

\section{Statistical Analysis}

All data are presented as sample number with percentages in parenthesis, unless otherwise indicated. Continuous variables are expressed as mean $( \pm \mathrm{SD})$ or median (range). Comparisons on categorically scaled variables between groups were examined using a nonparametric Fisher's exact $\chi^{2}$ test. Statistically significant differences in means or proportions were considered achieved at a $P$-value $\leq 0.05$, two-tailed. All statistical
TABLE I. Demographics and Clinical Characteristics

\begin{tabular}{lc}
\hline & $N$ \\
\hline Age (yrs) Median (range) & $26(18-78)$ \\
Males (\%) & $285(49)$ \\
Weight (kg) Median (range) & $67(31-164)$ \\
Reason for cardiac catheterization & \\
Diagnostic (\%) & $193(34)$ \\
Interventional (\%) & $378(66)$ \\
Missing data (\%) & $5(0.7)$ \\
Disease classification & \\
Minor CHD (\%) & $134(23)$ \\
Complex CHD (\%) & $387(67)$ \\
Arrhythmias only (\%) & $51(9)$ \\
Assumed PFO (\%) & $4(0.7)$ \\
Hypertension (\%) & $39(7)$ \\
Stroke/transient ischemic attack (\%) & $86(15)$ \\
NYHA Classification III and IV (\%) & $73(16)$ \\
General anesthesia (\%) & $310(53)$ \\
Medications (at least three medications) $(\%)$ & $135(23)$ \\
\hline
\end{tabular}

analyses were performed using Microsoft Excel and SPSS Version 11.5.

\section{RESULTS}

Baseline demographic and clinical data for the patient population are given in Table I.

A total of 576 catheterizations were performed on 436 adult patients during the 8.5-year study period. Complex CHD was present in 387/576 (67\%) procedures. The most common complex CHDs were: Tetralogy of Fallot with complete repair, 74/387 (19\%); Fontan palliation for single ventricle, 62/387 (16\%); simple transposition of the great arteries with Mustard palliation, 55/387 (14\%); and semilunar valve stenosis, $44 / 387$ (11\%). Minor CHD was present in 134/576 (24\%) procedures, including 115/576 (20\%) isolated ASD/PFO. In addition, there were four procedures in which a transesophageal echocardiogram (TEE) performed at an outside institution indicated a PFO, but no PFO was seen upon repeating a TEE in our PCL prior to cardiac catheterization. Arrhythmia diagnosis/treatment was performed in 51/576 (9\%) procedures in patients with structurally normal hearts. Only $3 / 576(<1 \%)$ procedures were performed on patients with known stable coronary artery disease. There were no patients with poorly controlled ischemic heart disease that required an urgent/ semiurgent CC in the PCL. General anesthesia was used in 310/576 (54\%) procedures of which $237(76 \%)$ were interventional procedures.

Interventional catheterization was performed in 378/ $576(66 \%)$ procedures (Table II). Percutaneous closure of ASD/PFO was the most common interventional procedure. General anesthesia was used during $75 \%$ of the ASD/PFO procedures. Intracardiac echocardiography was not available during the study period. 
TABLE II. Distribution of Interventional Cardiac

Catheterizations

\begin{tabular}{lc}
\hline Procedures & $n(\%)$ \\
\hline ASD/PFO closure & $115(30.6)$ \\
Pacemaker placement & $86(23)$ \\
Radio-frequency ablation & $49(13)$ \\
Angioplasty (pulmonary artery or & \\
$\quad$ systemic vein) & $49(13)$ \\
Others & $26(7)$ \\
Valvuloplasty & $21(5.6)$ \\
Biopsy & $20(5.3)$ \\
Coarctation stent/angioplasty & $6(1.6)$ \\
Angioplasty + pacemaker placement & $5(1.3)$ \\
Biopsy + pacemaker placement & $1(0.3)$ \\
\hline
\end{tabular}

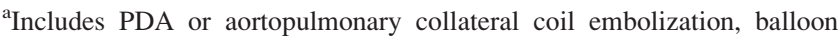
pericardiotomy, and thrombectomy.

Patients in group 1 (age $<45$ years) made up 480/ $576(83 \%)$ procedures and patients in group 2 (age $\geq$ 45 years) made up 96/576 (17\%) procedures (Table III). The occurrence of NYHA class 3 or 4 failure was not statistically different between group 1 and group 2 . The presence of complex CHD was significantly greater in group 1 than in group $2(77 \%$ vs. $19 \% ; P<0.01)$.

Patients older than 30 years were transferred from the PCL to the adjacent adult hospital if overnight stay was required for recovery (hospital policy). This occurred in $17.5 \%$ of the procedures.

Discharge from the hospital within $24 \mathrm{hr}$ of the procedure was accomplished in 508/576 (89\%) procedures.

Complications. A total of $61(10.6 \%)$ complications were encountered. There were 19 (3.2\%) major and 42 (7.3\%) minor complications. Hypotension was classified under major complications if inotropic support was required in addition to fluid resuscitation and under minor complications if fluid resuscitation alone was sufficient.

Major complications. Major complications (Table IV) were encountered during 10/387 (2.5\%) procedures in patients with complex CHD, in comparison to $9 / 189$ $(4.8 \%)$ procedures in patients without complex CHD $(P=\mathrm{NS})$. More than half of the major complications $(12 / 19)$ occurred during interventional procedures. The only death occurred in a 26-year-old patient during pacemaker placement because of postoperative complete atrioventricular block. The patient developed ventricular tachycardia that degenerated into fatal ventricular fibrillation. Major complications during device closure of ASD/PFO occurred in 7 patients of whom 3 had atrial flutter and 2 encountered hypotension. At follow-up of patients encountering atrial flutter, all 3 patients were in sinus rhythm and off anti-arrhythmic medication. Hypotension as a complication was seen in 7 procedures of which 6 were performed under general anesthesia. All episodes of hypotension are resolved by the end of the catheterization procedure with use of inotropic drips. ST segment elevation in the inferior leads was observed during closure of a PFO in one patient with a history of coronary artery bypass surgery. The elevation was transient and responded to administration of nitroglycerin and oxygen. There was no correlation between NYHA class and major complications.

Minor complications. Minor complications (Table V) occurred in 42/576 (7.3\%) catheterizations. The most frequent minor complications were vascular access site hematoma $(n=20)$ and isolated transient hypotension $(n=5)$ that was responsive to volume resuscitation. All vascular site hematomas resolved spontaneously within 1 week of the procedure.

Comparison between groups 1 and group 2. Complications, overall, were significantly more likely to occur in group 2 in comparison to group $1(P<0.01)$. There were no significant differences between group 1 and group 2 with regard to number of major complications (Table V). Group 2 had a significantly higher incidence of minor complications $(P<0.05)$. Group 2 was also significantly more likely to have hypotension (requiring fluid and/or inotropes) (7/96) compared with that of group $1(5 / 480), P=0.001$. There was no significant difference in the incidence of hematomas between the two groups.

\section{DISCUSSION}

Cardiac catheterization of adults with CHD presents a unique situation. Although adult cardiologists are clearly more experienced in performing adult catheterizations and in dealing with other comorbid adult issues, pediatric cardiologists have more experience in catheterization of patients with CHD. Also, a PCL has biplane imaging with its obvious advantages for a patient with complex CHD. With the prevalence of adults with CHD becoming greater, the question arises as to who is better equipped to treat this growing population. The optimal place to perform catheterization on adults with CHD has also not been determined. Additionally, although the complication rate for cardiac catheterizations in infants and children with CHD [7-11] and in adults with acquired heart disease is known $[12,13]$, there is no information on the complication rate in performing cardiac catheterizations in adults with CHD.

In this study of adults with CHD catheterized in a pediatric facility, the overall complication rate was $10.6 \%$ with a mortality rate of $0.17 \%$. This is similar to the reported complication rate of $8-12 \%$ and mortality rate of $0.14-0.5 \%$ for pediatric patients with CHD catheterized in a pediatric facility [7-11]. However, it must be noted that this comparison is with studies per- 
TABLE III. Comparison of Procedures Performed on Patients $<45$ Years or $\geq 45$ Years

\begin{tabular}{lccr}
\hline & $\begin{array}{c}\text { Group } 1 \\
\text { (age }<45 \text { yrs; } \\
n=480)(\%)\end{array}$ & $\begin{array}{c}\text { Group 2 } \\
\text { (age } \geq 45 \text { yrs; } \\
n=96)(\%)\end{array}$ & $P$ \\
\hline Mean age \pm SD (yrs) & $26 \pm 7$ & $54 \pm 7.7$ & $<0.01$ \\
Males & 250 & 34 & $<0.01$ \\
NYHA failure class 3 or 4 & $58(12)$ & $15(16)$ & 0.31 \\
Coronary artery disease & 0 & $3(3)$ & $<0.01$ \\
Complex CHD & $369(77)$ & $18(19)$ & $<0.01$ \\
Procedures on patients with TGA with & & & \\
$\quad$ Mustard repair or Tetralogy repair or & & & $<0.01$ \\
Fontan palliation in the complex & $189(39)$ & $2(2)$ & $<0.01$ \\
$\quad$ CHD group & $300(63)$ & $68(70)$ & $<0.01$ \\
Number of interventional catheterizations & $47(9.8)$ & $3(3)$ & $<0.01$ \\
ASD/PFO closure (\% of all procedures) & $83(17)$ & $18(19)$ & 0.04 \\
Pacemaker placement & $43(9)$ & $12(11.5)$ & 0.10 \\
Complications & $30(6.3)$ & $6(6.3)$ & $<0.01$ \\
$\quad$ Minor Complications & $13(2.7)$ & & \\
$\quad$ Major Complications & & $7(7)$ & \\
$\quad$ Hypotension (requiring fluids & $5(1)$ & & \\
$\quad$ and/or inotropes) & & & \\
\hline
\end{tabular}

TABLE IV. Major Complications

\begin{tabular}{|c|c|c|c|c|c|}
\hline & Complication & Age (yrs) & Diagnosis & Procedure & Disposition \\
\hline 1. & $\begin{array}{l}\text { Sustained ventricular } \\
\text { tachycardia/fibrillation }\end{array}$ & 26 & VSD repaired, complete AV block & Pacemaker placement & Death \\
\hline 2. & Ventricular fibrillation & 31 & $\begin{array}{l}\text { Complex single ventricle } \\
\text { s/p Fontan }\end{array}$ & Diagnostic & Defibrillation \\
\hline 3. & Atrial flutter & 52 & PFO & PFO closure & $\begin{array}{l}\text { Institution of antiarrhythmic } \\
\text { medication }\end{array}$ \\
\hline 4. & Atrial flutter & 44 & ASD & ASD closure & $\begin{array}{l}\text { Institution of antiarrhythmic } \\
\text { medication }\end{array}$ \\
\hline 5. & Atrial flutter & 55 & ASD & ASD closure & $\begin{array}{l}\text { Institution of antiarrhythmic } \\
\text { medication }\end{array}$ \\
\hline 6. & Hemothorax & 25 & Tricuspid atresia s/p Fontan & Hemodynamic evaluation & Placement of chest tube \\
\hline 7. & Pneumothorax & 25 & Truncus arteriosus repaired, AV block & Pacemaker placement & Placement of chest tube \\
\hline 8. & Retroperitoneal hematoma & 37 & $\mathrm{PFO}$ & PFO closure & $\begin{array}{l}\text { Spontaneous resolution; no } \\
\text { intervention }\end{array}$ \\
\hline 9. & Aortic dissection & 40 & Coarctation of aorta & Stent placement & Antihypertensive drips \\
\hline 10. & Renal failure & 19 & $\begin{array}{l}\text { DILV, s/p Fontan; congestive } \\
\text { heart failure }\end{array}$ & $\begin{array}{l}\text { Coil embolization of } \\
\text { collaterals }\end{array}$ & Dialysis \\
\hline 11. & $\begin{array}{l}\text { Balloon rupture/stent } \\
\text { malposition }\end{array}$ & 18 & L-TGA, VSD, PS s/p repair & Stent placement in conduit & Repositioning of stent \\
\hline 12. & Hypotension & 52 & Assumed PFO & $\begin{array}{l}\text { TEE, right heart } \\
\text { catheterization }\end{array}$ & Inotrope infusion \\
\hline 13. & Hypotension & 22 & Tetrology of Fallot/pulmonary atresia & Hemodynamic evaluation & Inotrope infusion \\
\hline 14. & Hypotension & 65 & Assumed PFO & $\begin{array}{l}\text { TEE, right heart } \\
\text { catheterization }\end{array}$ & Inotrope infusion \\
\hline 15. & Hypotension & 18 & TGA/Mustard repair & Hemodynamic evaluation & Inotrope infusion \\
\hline 16. & Hypotension & 40 & $\mathrm{PFO}$ & PFO closure & Inotrope infusion \\
\hline 17. & Hypotension & 24 & $\begin{array}{l}\text { Pulmonary atresia/intact ventricular } \\
\text { septum }\end{array}$ & Hemodynamic evaluation & Inotrope infusion \\
\hline 18. & Hypotension & 52 & ASD & ASD closure & Inotrope infusion \\
\hline 19. & ST segment elevation & 58 & $\mathrm{PFO}$ & PFO closure & Nitroglycerin and oxygen \\
\hline
\end{tabular}

$\mathrm{AV}$ block = atrio-ventricular block, DILV = Double Inlet Left Ventricle, PS= Pulmonic Stenosis, TEE $=$ Trans Esophageal Echocardiography, TGA= Transposition of the Great Arteries.

formed at least 5 years ago; there are no other recent studies available. The rate is also similar to the complication rate of $8 \%$ and a mortality rate of $0.2 \%$ in adults catheterized at an adult facility secondary to acquired heart disease $[12,13]$. In our experience, major complications were not significantly associated with the older subset of patients, interventional procedures, or with procedures on patients with complex CHD. 
TABLE V. Minor Complications

\begin{tabular}{lc}
\hline & $n$ \\
\hline Hematoma (access site) $^{\mathrm{a}}$ & 20 \\
Hypotension & 5 \\
Urethral Trauma - Foley induced & 1 \\
Angioplasty balloon rupture & 4 \\
Atrial Flutter & 2 \\
Ventricular Tachycardia & 1 \\
Hypoxia & 2 \\
Hemoptysis & 1 \\
Airway obstruction & 1 \\
Arm numbness, back ache & 1 \\
Laceration at venipuncture site & 1 \\
Anaphylaxis not requiring intubation & 1 \\
Ileus post CC & 1 \\
Renal colic & 1 \\
\hline
\end{tabular}

${ }^{\mathrm{a}}$ One patient in the study group had a hematoma along with hypotension.

One concerning complication encountered in performing cardiac catheterization in adults in our PCL was that of hypotension. Although 9 of 12 patients who developed hypotension during cardiac catheterization received general anesthesia, because of the small numbers, the use of general anesthesia did not reach statistical significance as a causative factor. In our experience, patients $>45$ years old were significantly more likely to develop hypotension. A blunted heart rate response to vasodilatation secondary to anesthesia is the most likely etiology in these patients. This is a potentially significant issue in the patient having a past history of a cerebral vascular accident or ischemic heart disease. It has become our practice that during induction of anesthesia, the blood pressure is measured noninvasively every $2 \mathrm{~min}$, and if there is any concern, an arterial line is placed for the patient.

Of the other major complications encountered, most were related to the technical aspects of performing the particular intervention. The incidence of atrial flutter during device closure of $\mathrm{ASD} / \mathrm{PFO}$ has been reported at $4 \%$ in the literature [14], which was similar to our experience $(2.6 \%)$. In two other patients, technical complications during stent placement for treatment of native coarctation of the aorta and conduit stenosis were encountered. We believe that in each of these situations, performance of the catheterization procedure in a PCL was not felt to have played a role in encountering these particular major complications.

Only 3 patients had coronary artery disease in the study population. It is expected that with an older population we would have had a higher percentage of coronary artery disease. Our strategy, however, would have remained the same: we would have referred a poorly controlled patient to the adult cardiologist for optimization of therapy prior to taking the patient to the PCL.
Notably, none of the 96 patients with age $\geq 45$ years had a CHD-related urgent or semi-urgent issue that necessitated a CC in a PCL prior to optimization of therapy for other comorbid conditions.

The 32nd Bethesda Conference on adults with CHD [15] emphasized the need for creation of regional adult CHD centers where adult and pediatric cardiologists would collaborate in the care of such patients under one roof. This would be the ideal situation. Until such time that these centers are widespread, our results suggest that the PCL may be a safe place for cardiac catheterization of adults with CHD after appropriate screening.

Limitations. This study is limited by its retrospective nature.

\section{CONCLUSIONS}

This study suggests that adults patients with CHD undergoing catheterization in a PCL have a complication risk equal to that of children with CHD undergoing catheterization. The older subset of adult patients are more likely to encounter complications overall. In older patients with CHD, general anesthesia should be used only when necessary and invasive blood pressure monitoring may be prudent under certain circumstances. With screening in place, it is safe to perform cardiac catheterization on most adults with CHD in a PCL.

\section{REFERENCES}

1. Webb GD, Williams RG. Care of the adult with congenital heart disease. J Am Coll Cardiol 2001;37:1161-1198. Presented at the 32nd Bethesda Conference, Bethesda, Maryland, October 2-3, 2000.

2. Warnes CA, Liberthson R, Danielson GK, Dore A, Harris L, Hoffman JI, Somerville J, Williams RG, Webb GD. Task force 1: the changing profile of congenital heart disease in adult life. J Am Coll Cardiol 2001;37:1170-1175.

3. Brickner ME, Hillis LD, Lange RA. Congenital heart disease in adults-first of two parts. N Engl J Med 2000;342:256-263.

4. Brickner ME, Hillis LD. Congenital heart disease in adultssecond of two parts. N Engl J Med 2000;342:334-342.

5. Webb CL, Jenkins KJ, Karpawich PP, Bolger AF, Donner RM, Allen D, Barst RJ, Congenital Cardiac Defects Committee of the American Heart Association Section on Cardiovascular Disease in the Young. Collaborative care for adults with congenital heart disease. Circulation 2002;105:2318-2323.

6. Therrien J, Webb G. Clinical update on adults with congenital heart disease. Lancet 2003;362:1305-1313.

7. Zeevi B, Berant M, Fogelman R, Galit BM, Blieden LC. Acute complications in the current era of therapeutic cardiac catheterization for congenital heart disease. Cardiol Young 1999;9:266-272.

8. Stanger P, Heymann MA, Tarnoff H, Hoffman JIE, Rudolf AM, Complications of cardiac catheterization of neonates, infants, and children: a three year study. Circulation 1974;50:596-608.

9. Vitiello R, McCrindle BW, Nykanen D, Freedom RM, Benson LN. Complications associated with pediatric cardiac catheterization. J Am Coll Cardiol 1998;32:1433-1440. 
10. Cassidy SC, Schmidt KG, Van Hare GF, Stanger P, Teitel DF. Complications of pediatric cardiac catheterization: a 3-year study. J Am Coll Cardiol 1992;19:1285-1293.

11. Fellows KE, Radtke W, Keane JF, Lock JE. Acute complications of catheter therapy for congenital heart disease. Am J Cardiol 1987;60:679-683.

12. Chandrasekar B, Doucet S, Bilodeau L, Crepeau J, deGuise P, Gallo R, Cote G, Bonan R, Joyal M, Gosselin G, et al. Complications of cardiac catheterization in the current era: a single center experience. Catheter Cardiovasc Interv 2001;52:289295.
13. Wyman RM, Safian RD, Portway V, Skillman JJ, McKay RG, Baim DS. Current complications of diagnostic and therapeutic cardiac catheterization. J Am Coll Cardiol 1988;12:1400-1406.

14. Chessa M, Carminati M, Butera G, Bini RM, Drago M, Rosti L, Giamberti A, Pome G, Bossone E, Frigiola A. Early and late complications associated with transcatheter occlusion of secundum atrial septal defect. J Am Coll Cardiol 2002;39:10611065.

15. Landzberg MJ, Murphy DJ Jr, Davidson WR Jr, Jarcho JA, Krumholz HM, Mayer JE Jr, Mee RB, Sahn DJ, Van Hare GF, Webb GD, et al. J Am Coll Cardiol 2001;37:1187-1193. 